\title{
Synthesis of some New Fused Pyrimidine Compounds
}

\author{
Shaymaa K. Younis" \\ **Maysa'a K. Shaker \\ *Department of Chemistry/College of Science/ University of Mosul \\ **Department of Chemistry/ College of Education for Girls/ University of Mosul \\ Email : khazaalyounis@yahoo.com \\ Maysaa.Emad@yahoo.com
}

(Received 21/7/2013;Accepted 7/10/2013)

\begin{abstract}
Biginelli reaction is a one-pot reaction which is used to prepare some of fused pyrimidine (2Amino-4-aryl-7, 7- dimethyl-1, 4, 5, 6, 7, 8-hexahydro quinazoline-5-one) ( $\left.\mathrm{A}_{1-6}\right)$ by the action of dimedone, guanidenium hydrochloride and some substituted benzaldehyde in presence of Lewis acid represented by boric acid ( $20 \%$ mole) .

These compounds were used later as precursors to prepare a superim type of schiff bases represented by compounds (2-Amino-4-aryl-5-hydrazono-7, 7-dimethyl-1, 4, 5, 6, 7, 8-hexahydro quinazoline) $\left(\mathrm{B}_{1-6}\right)$.

The assigned structure of the prepared compounds was corroborated by available physical and spectral methods.
\end{abstract}

Keywords: Biginelli reaction, dimedone, guanidenium hydrochloride, schiff bases.

\section{تحضير عددمن مركبلت البيريمين المالحمة الجينة}

\section{الملغص}

لستخدم تفاعل بجنيلي ذي الغطوة الولحة في تحضير بعض معوضلت البيريمينن الملتحمة والمتمثلة بالمركبت 2 -

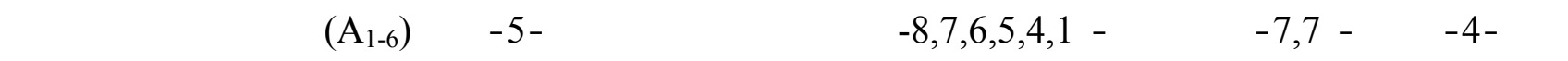
الدايميدون وهيدروكلوريد الكوانيين وعدد من معوضلت البنزالديهايد بوجود حلمض لويب المتمل بحلمض البوريك (20 البيل مول). كما لستخدت المركبك (A1-6) بوصفها مادة أولية جيدة في تحضير عدد من قواعدشيف الجيدة والمتمثلة بالمركبلت

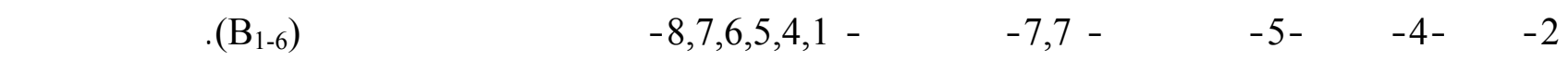
المركبت المحضرة بلستخده الطرائق الفيزيائية والطيفية المتوفرة.

الهاملت الدالة: قفاعل بجنيلي، الدايميدون، هيدروكلوريد الكوانيين، قواعدشيف.

\section{INTRODUCTION}

Three component one-pot condensation reaction has been emerged as a useful method in organic synthesis because the combination of three components to generate a new product in a single step is extremely economical among the multicomponent reaction (Huang et al.,2005; Orru and Groen, 2009; Ryabukhin et al., 2010) and efficient (Sun et al., 2008; Abdel hamid et al., 2011).

Additionally, this type of reaction received a great deals of attention in medical chemistry for various reasons, it's put on speed, diversity and efficiency in the drug discovery process (Müller, 2011). 
Biginelli reaction is an efficient one-pot multicomponent condensation reaction that is used widely in organic and medical chemistry (Bose et al., 2005; Kulkarn et al., 2009; Mochaddas et al., 2012). Starting from aldehyde, Urea(thiourea) and $\beta$-keto ester under strongly acidic condition represented by Lewis acid to obtaine the pyrimidine-2-one analogs (Kappe, 1993; Mohammadizadeh and Firoozi, 2011), which received a significant attention owing to their biological (Shutalev et al., 1998; Mobinikhaledi and Kalhor, 2010) and pharmaceutical properties (Phucho et al., 2009; Piqani and Zhang, 2011; Shaikh et al., 2012) such as antihypertensive(Atwal et al., 1989; Atwal et al., 1990), antiinflammatory and antibacterial (Jadhav et al., 2012; Badadhe et al., 2011, Akbas et al., 2010) and antimicrobial (Beena and Akelesh, 2012) were also studied depending on this type of synthesis.

Recently, dihydro pyrimidine derivatives have been considered for the development of new anticancer drugs (Heda et al., 2009; Kumar et al., 2009) and antimalaria drugs (Sandhu and Sandhu, 2012).

In this presentation, Biginelli reaction was used to prepare a special type of fused pyrimidine derivatives starting from 1,3- cycloketone represented by dimedone, guanidenium hydrochloride and substituted benzaldehyde in presence of boric acid (20\% mole).

This reaction proceeded through conventional method to obtained compounds 2-amino-4-aryl7, 7-dimethyl-1, 4, 5, 6, 7, 8-hexahydro quinazolin-5-one $\left(\mathrm{A}_{1-6}\right)$, which is then used as good synthon to prepare another type of schiff bases represented by compounds 2-amino -4-aryl-5-hydrazono-7, 7-dimethyl-1, 4, 5, 6, 7, 8- hexahydro quinazoline compounds $\left(\mathrm{B}_{1-6}\right)$.

\section{EXPERIMENTAL}

Melting points (M.P.) were measured on Electrothermal SMP30- Stuart melting point apparatus and were uncorrected. Infrared (FT-IR) spectra were recorded as (KBr) disk using a Bruker, FT-IR, spectrophotometer Tensor 27. Ultraviolet (U.V) spectra were performed on Shimadzu UV-visible Spectrophotometer UV-1660 PC using methanol as a solvent. Thin layer chromatography (TLC) was carried out on silica gel $(120 \mathrm{mesh})$ coated plates $(2 \times 10) \mathrm{cm}$, activated for one hour at $\left(110-120^{\circ} \mathrm{C}\right)$ before use and the plates were developed with iodine vapor.

\section{Synthesis of 2-amino-4-aryl-7,7-dimethyl-1, 4, 5, 6, 7, 8-hexahydro quinazolin-5-one (A 1 -6): Method A: (Meshram et al., 2012)}

A mixture of dimedone $(0.002 \mathrm{~mole} / 0.280 \mathrm{gm})$, aromatic aldehyde $(0.002 \mathrm{~mole})$, guanidenium hydrochloride ( 0.002 mole/ $0.190 \mathrm{gm})$ and boric acid ( $20 \%$ mole) was dissolved in absolute ethanol $(25 \mathrm{ml})$ in flask equipped with condenser and dry calcium chloride tube. The mixture was refluxed for $(5 \mathrm{hrs}$.), cooling then poured into $(50 \mathrm{ml})$ ice- water. The coloured precipitate was filtered off and washed thoroughly with water and recrystallized from ethanol-water to yield compounds $\left(\mathrm{A}_{1-6}\right)$. The completion of the reaction was monitored by thin layer chromatography (T.L.C), the physical and spectral data were listed in Table (1).

\section{Method B: (Hügel, 2009; Chebanov et al., 2010)}

A mixture of dimedone $(0.005$ mole / 0.7 gm), guanidenium hydrochloride ( 0.005 mole $/ 0.5 \mathrm{gm})$ and aromatic aldehyde $(0.005 \mathrm{~mole})$ was dissolved in xylene $(10 \mathrm{ml})$ and refluxed with catalytic amount of triethyl amine (T.E.A.) $(0.3 \mathrm{ml})$ for $(5 \mathrm{hrs}$.). Cooling and poured into (50 ml) ice- water and then extracted with water $(3 \times 10 \mathrm{ml})$. The organic layer was then dried and the crud gummy product was solidified with ether. Finally, the product recrystallized from ethanol to give compounds $\left(\mathrm{A}_{1-6}\right),($ Table 1$)$. 
Table 1: Physical properties and spectral data for compounds $\left(A_{1-6}\right)$

\begin{tabular}{|c|c|c|c|c|c|c|c|c|c|c|c|}
\hline \multirow[b]{2}{*}{$\begin{array}{c}\text { Comp. } \\
\text { No. }\end{array}$} & \multirow[b]{2}{*}{ G } & \multirow[b]{2}{*}{ M.P. $\left({ }^{\circ} \mathbf{C}\right)$} & \multirow{2}{*}{$\begin{array}{c}\text { Yield } \\
(\%)\end{array}$} & \multirow{2}{*}{$\begin{array}{c}\mathbf{R}_{\mathbf{f}} \text { Value } \\
\text { (ethyl } \\
\text { acetate: } \\
\text { benzene) } \\
(2: 8) \text { ratio }\end{array}$} & \multirow{2}{*}{$\begin{array}{c}\text { UV } \\
(\mathbf{M e O H}) \\
\lambda_{\max }(\mathbf{n m})\end{array}$} & \multicolumn{6}{|c|}{ I.R $(\mathrm{KBr}) v\left(\mathrm{~cm}^{-1}\right)$} \\
\hline & & & & & & $\mathbf{N H}_{2}$ & N-H & $\mathbf{C}=\mathbf{O}$ & $\begin{array}{c}\mathrm{C}=\mathrm{C} \\
\text { (cycl.) }\end{array}$ & $\begin{array}{c}\mathrm{C}=\mathbf{N} \\
\text { (cycl.) }\end{array}$ & others \\
\hline $\mathbf{A}_{1}$ & & $202-204$ & 94 & 0.473 & 236 & 3320 & 3112 & 1660 & 1624 & 1612 & - \\
\hline $\mathbf{A}_{2}$ & & $190-193$ & 67 & 0.169 & 296 & 3311 & 3228 & 1651 & 1610 & 1593 & $\begin{array}{c}\mathrm{NO}_{2} \\
\text { asym } 1516 \\
\text { sym } 1338\end{array}$ \\
\hline $\mathbf{A}_{3}$ & & $134-136$ & 71 & 0.475 & 262 & 3309 & 3240 & 1666 & 1604 & 1589 & $\begin{array}{c}\text { acyclic } \\
\text { C-O-C, } \\
1196\end{array}$ \\
\hline $\mathbf{A}_{4}$ & & $85-87$ & 69 & 0.283 & 264 & 3338 & 3140 & 1670 & 1595 & 1547 & - \\
\hline $\mathbf{A}_{5}$ & 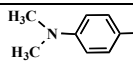 & $189-191$ & 74 & 0.396 & 260 & 3333 & 3205 & 1660 & 1602 & 1593 & - \\
\hline$A_{6}$ & & 193-195 & 67 & 0.339 & 294 & 3311 & 3168 & 1662 & 1616 & 1593 & $\begin{array}{c}\text { cyclic } \\
\text { C-O-C, } \\
1257\end{array}$ \\
\hline
\end{tabular}

Synthesis of 2-amino-4-aryl-5-hydrazono-7, 7-dimethyl-1, 4, 5, 6, 7, 8-hexahydro quinazo- line (B $\left.{ }_{1-6}\right)$ : (Solvam et al., 2010 )

A mixture of compounds $\left(\mathrm{A}_{1-6}\right)(0.001$ mole) and hydrazine hydrate $(80 \%)(0.001 \mathrm{~mole})$ was treated with anhydrous sodium acetate $(0.001$ mole $/ 0.082 \mathrm{gm})$ and glacial acetic acid $(5 \mathrm{ml})$ in presence of abs. ethanol $(10 \mathrm{ml})$ as solvent and then refluxed for $(3 \mathrm{hrs}$.). After standing for approximately $(24 \mathrm{hrs}$.) at room temperature. The precipitated product was separated by filteration and washed thoroughly with hot water to yield compounds $\left(\mathrm{B}_{1-6}\right)$. The progress of the reaction was followed by (T.L.C), the physical and spectral data were listed in Table (2).

Table 2: Physical properties and spectral data for compounds $\left(\mathrm{B}_{1-6}\right)$

\begin{tabular}{|c|c|c|c|c|c|c|c|c|c|c|c|}
\hline \multirow[b]{2}{*}{$\begin{array}{c}\text { Comp. } \\
\text { No. }\end{array}$} & \multirow[b]{2}{*}{$\mathbf{G}$} & \multirow[b]{2}{*}{ M.P. $\left({ }^{\circ} \mathbf{C}\right)$} & \multirow[b]{2}{*}{$\begin{array}{l}\text { Yield } \\
(\%)\end{array}$} & \multirow{2}{*}{$\begin{array}{c}\mathbf{R}_{\mathbf{f}} \text { Value } \\
\text { (ethyl } \\
\text { acetate: } \\
\text { benzene) } \\
(2: 8) \text { ratio }\end{array}$} & \multirow{2}{*}{$\begin{array}{c}\text { UV } \\
(\mathrm{MeOH}) \\
\lambda_{\max }(\mathbf{n m})\end{array}$} & \multicolumn{6}{|c|}{ I.R (KBr) v $\left(\mathrm{cm}^{-1}\right)$} \\
\hline & & & & & & $\mathbf{N H}_{2}$ & NH & $\begin{array}{c}\mathrm{C}=\mathrm{C} \\
\text { (cycl.) }\end{array}$ & $\begin{array}{c}\mathbf{C}=\mathbf{N} \\
\text { (imin) }\end{array}$ & $\begin{array}{c}\mathrm{C}=\mathrm{N} \\
\text { (cycl.) }\end{array}$ & others \\
\hline $\mathrm{B}_{1}$ & Bd & $73-75$ & 56 & 0.255 & 234 & 3330 & 3203 & 1620 & 1562 & 1493 & - \\
\hline $\mathrm{B}_{2}$ & & $125-127$ & 84 & 0.415 & 254 & 3340 & 3205 & 1612 & 1562 & 1514 & $\begin{array}{c}\mathrm{NO}_{2} \\
\text { asym } \\
1472 \\
\text { sym } \\
1342 \\
\end{array}$ \\
\hline $\mathrm{B}_{3}$ & $\mathrm{CH}_{3} \mathrm{O}$ & $129-130$ & 54 & 0.698 & 220 & 3373 & 3224 & 1604 & 1508 & 1454 & $\begin{array}{c}\text { acyclic } \\
\text { C-O-C, } \\
1167\end{array}$ \\
\hline $\mathrm{B}_{4}$ & $\mathrm{cl}-$ & $77-79$ & 64 & 0.364 & 234 & 3359 & 3213 & 1620 & 1542 & 1491 & - \\
\hline $\mathrm{B}_{5}$ & 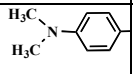 & $249-251$ & 67 & 0.596 & 244 & 3263 & 3124 & 1604 & 1523 & 1479 & - \\
\hline $\mathrm{B}_{6}$ & & 136-138 & 50 & 0.400 & 242 & 3325 & 3205 & 1620 & 1562 & 1485 & $\begin{array}{c}\text { cyclic } \\
\text { C-O-C, } \\
1230\end{array}$ \\
\hline
\end{tabular}




\section{RESULTS AND DISCUSSION}

In order to optimize the reaction conditions, we firstly used triethyl amine as a base to prepare compounds $\left(\mathrm{A}_{1-6}\right)$ and then repeated this reaction under acidic condition according to Biginelli reaction condition by using boric acid $(20 \%$ mole). This change in reaction condition from basic to acidic proved that the two methods give the same products $\left(\mathrm{A}_{1-6}\right)$ as shown in equation (1).<smiles>CC1(C)CC(=O)C=C(O)C1</smiles>

Dimedone<smiles>NC(N)=NCl</smiles>

Guanidinium hydrochloride<smiles>[Y]C1N=C(N)NC2=C1C(=O)CC(C)(CC)C2</smiles>

$\left(A_{1-6}\right)$<smiles>Cc1ccc(CCc2ccc(OCc3ccc(OCc4ccc(N(C)C)cc4)cc3)cc2)cc1</smiles>

Definitely, the acidic condition gave a higher yield than the basic condition, therefore the acidic conditions were adopted to prepare the required compounds $\left(\mathrm{A}_{1-6}\right)$ (Meshram et al., 2012; Tu et al., 2003). Furthermore, the reaction mechanism in basic conditions is completely different from that in acidic conditions. The reaction mechanism in basic conditions proceed through an ordinary nucleophilic attack of dimedone anion to the carbonyl carbon to afford $\alpha, \beta$-unsaturated compound (2-benzylidene-5,5-dimethylcyclohexane-1,3-dione) which then in turn underwent nucleophilic addition reaction with guanidinuim hydrochloride to obtained 1-((2-hydroxy-4,4-dimethyl-6oxocyclohex-1-enyl)(aryl) methyl) guanidine. Finally, intramolecular cycloaddition reaction will occur followed by losing of water molecule to form compound ( $\left.A_{1-6}\right)$, (Singh, 2011).

Whereas, in acidic condition, mechanistically, it is reasonable to assume that the reaction was proceeded firstly via protonation of the carbonyl group then it will undergo nucleophilic attack with guanidinium hydrochloride to afford the intermediate (I) which upon reaction with the enolated form of dimedone yielded the intermediate (II). Finally, intramolecular cycloaddition reaction takes place by the action of amino group on the carbonyl group to give the intermediate (III) followed by losing of water molecule to yield the corresponding compounds $\left(\mathrm{A}_{1-6}\right)$ as shown in scheme (1), (Hügel, 2009; Wang et al., 2010; Loto et al., 2012).

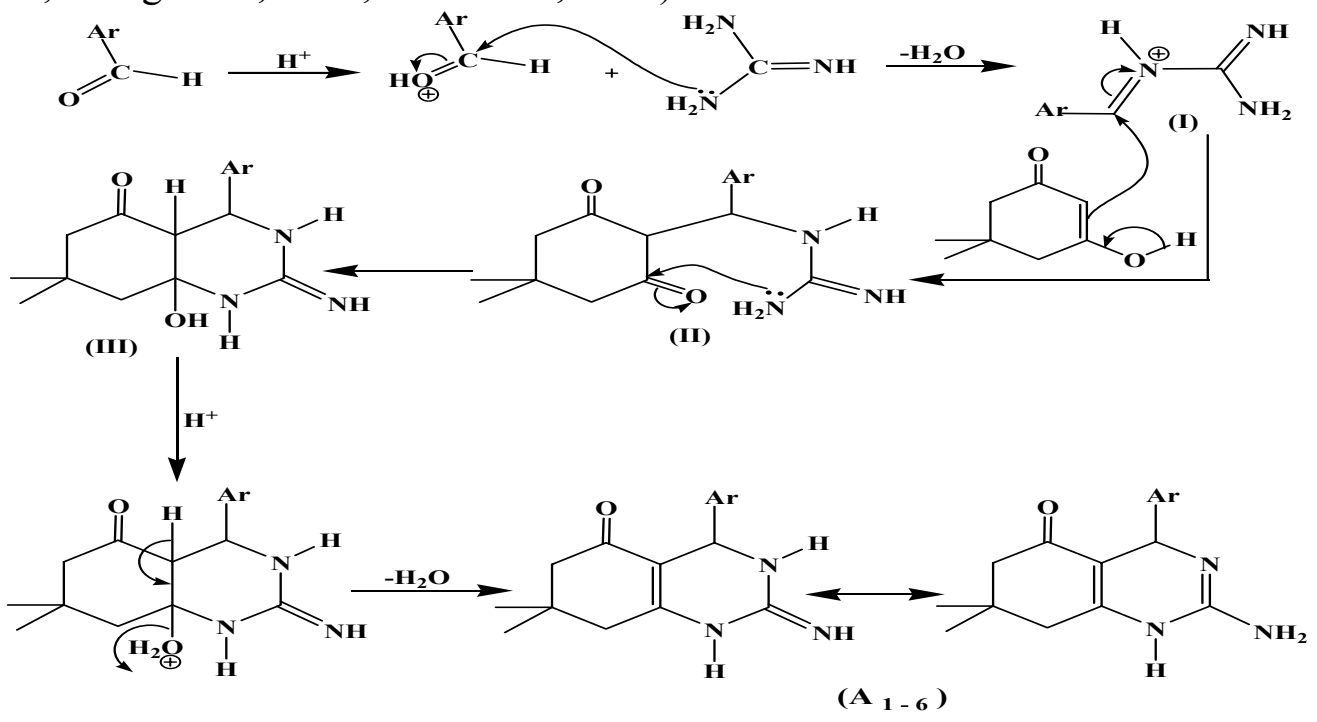


The structures of compounds $\left(\mathrm{A}_{1-6}\right)$ were confirmed by spectral methods represented by FT-IR and U.V. spectra as shown in Table (1).

In FT-IR spectra all compounds show absorption bands at $\left(3309-3338 \mathrm{~cm}^{-1}\right),\left(3112-3240 \mathrm{~cm}^{-1}\right)$, (1651-1670 $\left.\mathrm{cm}^{-1}\right),\left(1595-1624 \mathrm{~cm}^{-1}\right)$ and $\left(1547-1612 \mathrm{~cm}^{-1}\right)$ due to $\mathrm{NH}_{2}, \mathrm{NH}, \mathrm{C}=\mathrm{O}, \mathrm{C}=\mathrm{C}$ (cyclic) and $\mathrm{C}=\mathrm{N}$ (cyclic) functional groups respectively. Whereas, the U.V. spectra showed absorption bands at $\lambda_{\max }(236-296 \mathrm{~nm})$ due to the cyclic system and to the $n \rightarrow \pi^{*}$ transition (Finar,1977; Parikh, 1974).

Actually, our target in this work is not only to prepare new Biginelli products but to prove the ability of Biginelli products to act as a good synthon in organic synthesis. Thus, starting from this point and because the Biginelli products $\left(\mathrm{A}_{1-6}\right)$ having a carbonyl group in position 5 , the latter used as good synthon to prepare hydrazones represented by compounds $\left(\mathrm{B}_{1-6}\right)$ by the action of hydrazine hydrate $(80 \%)$ in presence of glacial acetic acid and sodium acetate. It is worth noting that, the use of acetic acid and sodium acetate together in this reaction is to keep the reaction under acidic medium (PH 3.7-5.6) (Dawson et al., 1986). The condensation reaction was found to proceed according to equation (2).

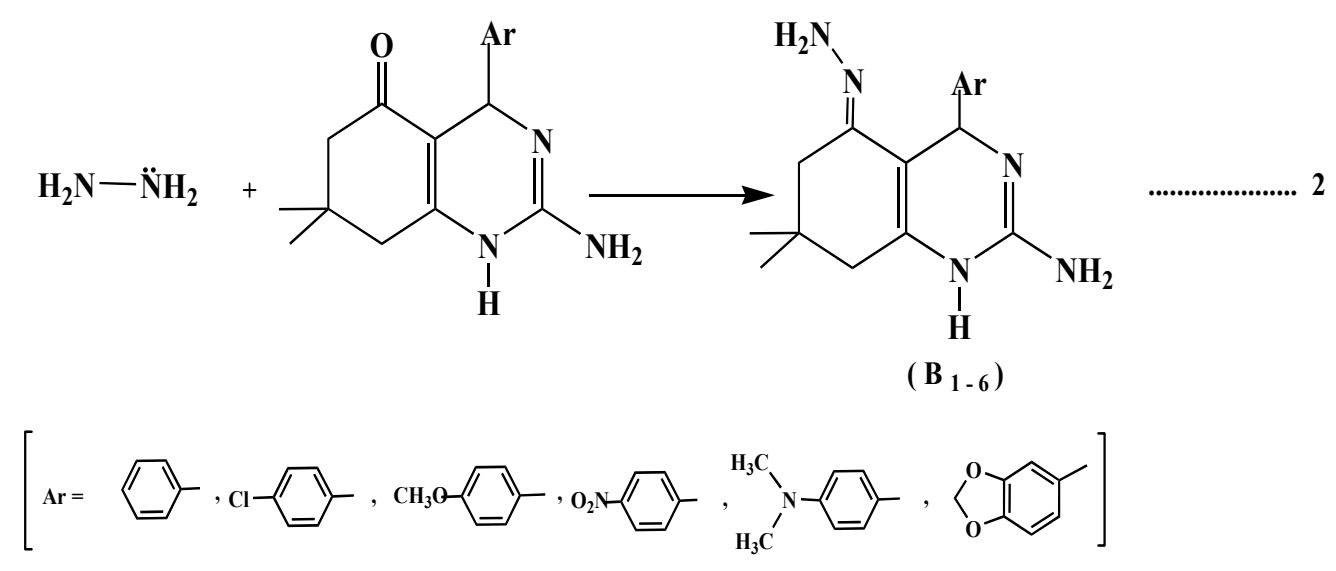

The more plausible mechanism for this reaction was summarized in scheme (2). (Schmid,1996; Clayden et al., 2001).

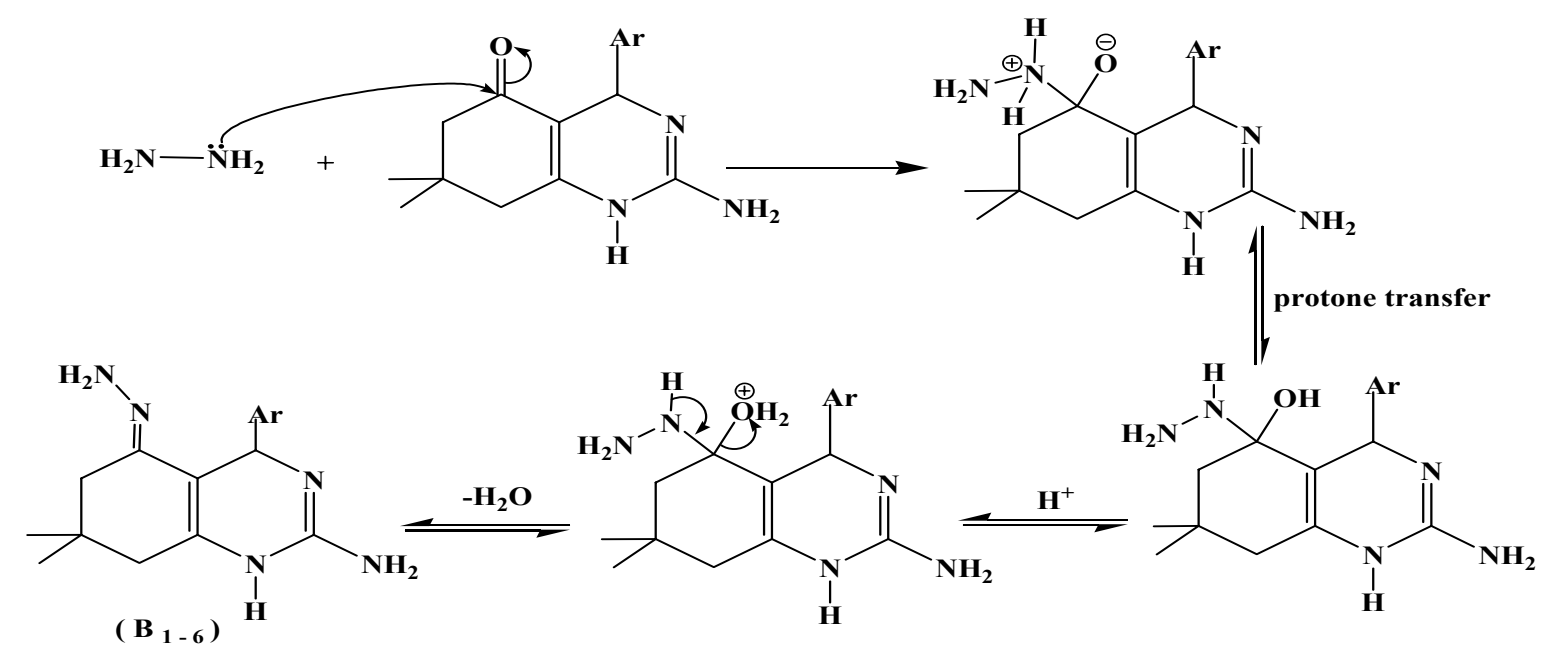

Scheme (2)

The structures of compounds $\left(\mathrm{B}_{1-6}\right)$ were established on the bases of their spectral data. Their IR spectra display appearance of absorption bands at $\left(3263-3373 \mathrm{~cm}^{-1}\right),\left(3124-3224 \mathrm{~cm}^{-1}\right)$, 
(1604-1620 $\left.\mathrm{cm}^{-1}\right),\left(1508-1562 \mathrm{~cm}^{-1}\right)$ and $\left(1454-1514 \mathrm{~cm}^{-1}\right)$ related to $\mathrm{NH}_{2}, \mathrm{NH}, \mathrm{C}=\mathrm{C}$ (cyclic), $\mathrm{C}=\mathrm{N}$ (imino) and $\mathrm{C}=\mathrm{N}$ (cyclic) functional groups respectively. The absence of keto absorption group at (1651-1670 $\mathrm{cm}^{-1}$ ) and the appearance of a strong absorption band in the range of (1508$1562 \mathrm{~cm}^{-1}$ ) attributable to $\mathrm{C}=\mathrm{N}$ (imino) provides an evidence for the formation of schiff bases $\left(\mathrm{B}_{1-6}\right)$. Also, these compounds have U.V. absorption band at $\lambda_{\max }(234-254 \mathrm{~nm})$ due to the $\mathrm{n} \rightarrow \pi^{*}$ transition comparing with those for compounds (A $1-6)$ (Finar, 1977; Parikh, 1974).

Finally, ethyl acetate: benzene, $(2: 8)$ was used as a suitable solvent system in $\mathrm{R}_{\mathrm{f}}$ thin layer chromatography measurements (Singh, 2011) to provide a suitable explanation about the formation of compounds $\left(\mathrm{A}_{1-6}\right)$ and $\left(\mathrm{B}_{1-6}\right)$ as shown in Tables (1) and (2) respectively.

\section{REFERENCES}

Abdelhamid, A.A.; Mohamed, S.K.; Maharramov, A.; Khalilov, A.; Allahverdiev, M. (2011). Facile and efficient synthesis of acridine diones from primary amino alcohol via threecomponent condensation reaction assisted by Microwave Irradiation, international conference on environment and bioscience. IPCBEE, 21,187 -193.

Akbas, E.; Levent, A.; Gümüs, S.; Rauf, M.; Akyazi, S.I. (2010). Synthesis of some novel pyrimidine derivatives and investigation of their electro chemical behavior. Bull Korean Chem. Soc., 31(12), 3632- 3638.

Atwal, K.S.; Rovnyak, G.C.; Kimball, S.D.; Floyd, D.M.; Moreland, S.; Swanson, B.N.; Gougoutas, D.Z.; Schewartz, J.; Smillie, K.M.; Malley, M.F. (1990). Dihydro pyrimidine calcium channel blockers,II. -3- substituted -4- aryl -1,4- dihydro -6- methyl -5pyrimidine carboxylic acid ester as potent mimics of dihydro pyridines. J. Med. Chem., 33(9), 2629-2635.

Atwal, K.S.; Rovnyak, G.C.; Oreilly, B.C.; Schewartz, J. (1989). Substituted-1,4-dihydro pyrimidines, synthesis of selectively functionalized-2-hetro-1,4-dihydro pyrimidines. $J$. Org. Chem., 54(25), 5898- 5907.

Badadhe, P.V.; Chate, A.V.; Hingane, D.G.; Mahajan, P.S.; Chavhan, N.M. ; Gill, C.H. (2011). Microwave-assisted one-pot synthesis of octahydroquinazolinone derivatives catalyzed by thiamine hydrochloride under solvent-free condition. J. Korean Chem. Soc., 55(6), 936-939.

Beena, K.P.; Akelesh, T. (2012). Synthesis and screening of some dihydropyrimidines derivatives as antimicrobial agents. Int. Res. J. Pharm., 3(9), 303-304.

Bose, D.S.; Sudharshan, M.; Chavhan, S.W. (2005). New protocol for Biginelli reaction a practical synthesis of monastrol. ARKIVOC, iii, 228 - 236.

Chebanov, V.A.; Gura, K.; Desenko, S. M. (2010). Aminoazoles as key reagent in Multicomponent heterocyclization. Top Heterocycl Chem., 23, $41-84$.

Clayden, J.; Greeves, N.; Warren, S.; Wother, P. (2001). "Organic Chemistry". Oxford University Press, Inc., New York, 349p.

Dawson, R.M.C.; Elliott, D.C.; Elliott, W.H.; Jones, K.M. (1986). "Biochemical Research". 3rd ed., Oxford Science Publications, pp. 1-580.

Finar, I.L. (1977). "Organic Chemistry". Longman, Vol. 2, pp.17-18.

Heda, L.C.; Sharma, R.; Pareek, C.; Chaudhari, P.B. (2009). Synthesis of antimicrobial activity of some derivatives of 5- substituted indol dihydropyrimidines. E. J. Chem., 6(3), 770 -774.

Huany, S.; Pan, Y.; Zhu, Y.; Li, A.W. (2005). A novel three- component one- pot reaction involving Alkyne, Urea or thiourea and aldehyde. Org. Lett., 7(17), 3797 - 3799.

Hügel, H.M. (2009). Microwave multicomponent synthesis. Molecules. 14, 4936-4972.

Jadhav, V.B.; Hallo, H.V.; Tekale, S.U.; Pawer, R.P. (2012). Bioactive dihydro pyrimidines An overview. Pelogia Res. Lib., 3(5), 1213 -1228. 
Kappe, C.O. (1993). 100 Years of the Biginelli dihydro- pyrimidine synthesis. Tetrahedron, 49(39), 6937- 6963.

Kulkarni, M.G.; Chavhan, S.W.; Shinde, M.P.; Gaikwad, D.D.; Borhade, A.S.; Dhondge, A.P.; Shaikh, Y.B.; Ningdal, V.B.; Desai, M.P.; Birhade, D.R. (2009). Zeolite catalyzed solvent - free one- pot synthesis of dihydro pyrimidin-2(1H)-ones- A practical synthesis of monastrol. Beilstein J. Org. Chem., 5(4), 1-4.

Kumar, B.R.P.; Sankar, G.; Baig, R.B.N.; Chandrashekaran, S. (2009). Novel Biginelli dihydropyrimidines with potential anti- cancer activity a parallel synthesis and CoMSIA study. Eur. J. Med.Chem., xxx, 1-7.

Loto, R.T.; Loto, C. A.; Popoola, A.P.I.; Ranyaoa, M. (2012).Pyrimidine derivatives as environmentally-friendly corrosion inhibitors: A review. Int. J. Phys. Sci., 7(14), 2136 2144.

Meshram, H.M.; Kumer, A.S.; Kumer, G.S.; Swetha, A.; Reddy, B.C.; Ramesh, P. (2012). Boric promoted an efficient and practical synthesis of fused pyrimidines in equeous media. Der. Pharm. Chem., 4(3), 956-960.

Mobinikhaledia, A.; Kalhob, M. (2010). Synthesis and biological activity of some oxo and thioxo pyrimidines. Int. J. Drug. Dev. And Res., 2 (2), 268 - 272.

Mochaddas, M.; Davoodnia, A.; Heravi, M.M.; Tavakoli- Hosein, N. (2012). Sulfonated carbon catalyzed Biginelli reaction for one- pot synthesis of 3,4-dihydro pyrimidine-2(1H)-ones and thiones. Chin. J. Catl., 33(4), $706-710$.

Mohammadizadeh, M.R.; Firoozi, N.A. (2011). Trifloro acetic acid as an effective catalyst for Biginelli reaction: one- pot dihydro pyrimidine-2- ones (and thiones). J. Chem., 8 (si), S266 - S270.

M ller, J.J. (2011), Multi component reactions. Beilstein J. Org. Chem., 7, 960 -961.

Orru, R.V.A.; Groen, M.B. (2009). "Multicomponent Reactions". EU and the Dutch Science Foundation (NWO/CERC3), pp. 1-124.

Parikh, V.M. (1974). "Absorption Spectroscopy of Organic Molecules". Addision Wesely Publishing Comp., Inc., $30 \mathrm{p}$.

Phucho, I.T.; Nongpiur, A.; Tumtin, S.; Nongrum, R.; Nongkhlow, R.L. (2009). Recent progress in the chemistry of dihydropyrimidenone. R. J. Chem., 2(3), 662- 676.

piqani, B.; Zhang, W. (2011). Synthesis and driverse dihydropyrimidine- related scaffolds by fluorous benzaldehyde- based Biginelli reaction and post condensation modification. Beilstein J. Org. Chem., 7, 1294- 1298.

Ryabukhin, S.V.; Plaskon, A.S.; Bondarenko, S.S.; Ostepehuk, E.N.; Grygorenko, O. O.; Shishkin, O.V.; Tolmachey, A. A. (2010). Acyl pyruvate as synthons in the Biginelli reaction. Tetrahedron Lett., 51, 4229 -4232.

Sandhu, S.; Sandhu, J.S. (2012). Past, present and future of the Biginelli reaction: a critical perspective. ARKIVOC , i, 66-133.

Schmid, G.H. (1996). "Organic Chemistry". Mosby -Year Book, Inc. pp.620-621.

Selvam, T.P.; Kumar, P.V.; Prakash, C.R. (2010). Synthesis and anti-microbial activity of novel thiazolo quinazoline derivatives. Int. J. Pharm. Pharm. Sci., 2(2), 118-122.

Shaikh, A.A.; Shaikh, Y.I.; Nazeruddin, G.M. (2012). Multicomponent reactions (MCRs) as a green approach towards the synthesis of various heterocyclic compounds. Int. J. Basic Appl. Chem. Sci., 2(4), 2277-2073.

Shatalev, A.D.; Kishko, E.A.; Sivova, N.V.; Kuznetsov, A.Y. (1993). A new convenient synthesis of 5-acyl-1,2,3,4- tetrahydro pyrimidine-2- thiones/ ones. Molecules, 3, $100-106$.

Singh, B. (2011). Study of tetra hydro-5H-5-(2'-hydroxyphenyl)-2-(4'-some substituted benzylidine)-3-(4-nitrophenyl amino) thiazolo quinazoline. Int. J. Pharm. Sci. Health Care, 1(1), 23-40. 
Solvam, T.P.; Kumar, P.V.; Kumar, A.S. (2010). Synthesis and anti- oxidant activity of novel-6,7,8,9- tetra hydro-5H-5-(2-hydroxy phenyl)-2-(4- substituted benzylidine)-3-(4nitro phenyl amino) thiazolo quinoline derivatives. Res. Biotechnology, 1, 38-48.

Sun, C.; Ji, S.J.; Liu, Y. (2008). A novel, simple and efficient synthesis of 3-amino-benzo [d] imidazo [2,1-b] thiazole derivatives via a multi componeat procedure. J. Chin. Chem. Soc., 55, $292-296$.

Tu, S.; Fang, F.; Miao, C.; Jiang, H.; Feng, Y.; Shi, D.; Wang, X. (2003). One-pot synthesis of 3,4dihydropyrimidin-2(1H)-ones using boric acid as catalyst. Tetrahedron Letters, 44 (32), 6153-6155.

Wang, X.; Ma, W.; Wu, L.; Yan, F. (2010). Synthesis of $2 H$-indazolo[2,1-b]phthalazine1,6,11(13H)-trione derivatives using wet cyanuric chloride under solvent-free Condition. J. Chin. Chem. Soc., 57, 1341-1345. 